The Journal of Laryngology \& Otology

http://journals.cambridge.org/JLO

Additional services for The Journal of Laryngology \& Otology:

Email alerts: $\underline{\text { Click here }}$

Subscriptions: $\underline{\text { Click here }}$

Commercial reprints: $\underline{\text { Click here }}$

Terms of use : $\underline{\text { Click here }}$

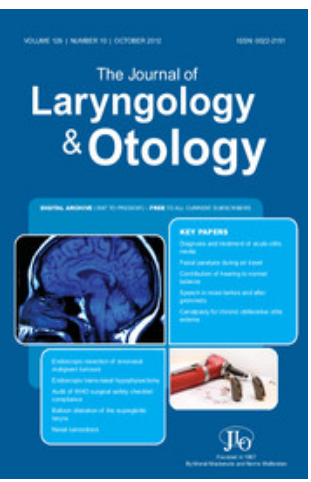

\title{
Non-cholesteatomatous suppurative otitis media: facial nerve palsy in an immunocompromised patient
}

C. Hartley, S. R. Saeed and T. J. Lyons

The Journal of Laryngology \& Otology / Volume 109 / Issue 08 / August 1995, pp 755 - 758

DOI: 10.1017/S0022215100131238, Published online: 29 June 2007

Link to this article: http://journals.cambridge.org/abstract_S0022215100131238

How to cite this article:

C. Hartley, S. R. Saeed and T. J. Lyons (1995). Non-cholesteatomatous suppurative otitis media: facial nerve palsy in an immunocompromised patient. The Journal of Laryngology \& Otology, 109, pp 755-758 doi:10.1017/S0022215100131238

Request Permissions : $\underline{\text { Click here }}$ 


\title{
Non-cholesteatomatous suppurative otitis media: facial nerve palsy in an immunocompromised patient
}

\author{
C. Hartley, F.R.C.S., S. R. SAEed, F.R.C.S., T. J. Lyons, M.R.C.Path.
}

\begin{abstract}
A 47-year-old man developed a complete facial nerve palsy secondary to non-cholesteatomatous suppurative otitis media. At operation, this was seen to be due to destruction of the nerve from halfway along the horizontal segment to a point just distal to the second genu. The history of recent renal transplantation and subsequent immunosuppression was judged to be significant in the pathogenesis of the palsy.
\end{abstract}

Key words: Otitis media, suppurative; Facial paralysis; Immunosuppression

\begin{abstract}
Introduction
Lower motor neurone facial palsy is a common condition with an estimated incidence of 20-25 cases per 100000 population annually (Sherwen and Thong, 1987). The aetiology of these palsies falls into two broad groups: 50 per cent are idiopathic (Bell's palsy), while in the remainder, a large group of underlying pathologies can be demonstrated after appropriate investigation (May, 1987). Amongst this latter group, three to four per cent of cases are associated with infection in the tympanomastoid region (Takahashi et al., 1985; May, 1987). In children, acute suppurative otitis media is the most common infective cause (May, 1987), though rarely serous otitis media is responsible (Premachandra and Radcliffe, 1989). In contrast. in adults, chronic suppurative otitis media (CSOM) is the more common infective cause. In this adult group. cholesteatoma is usually present, with exposure of the facial nerve within its tympanic portion (Takahashi et al. 1985: Savic and Djeric, 1989). Less commonly, specific chronic infections are responsible, such as tuberculosis or syphilis (De Paep et al., 1989; Linstrom et al., 1993). There remains, however, a small group of patients with CSOM in which cholesteatoma and specific infection are both absent. We present such a case occurring in an immunocompromised patient. in whom aggressive mucosal disease led to a complete facial palsy.
\end{abstract}

\section{Case history}

A 47-year-old man was referred to the ENT Department at Manchester Royal Infirmary shortly after receiving a cadaveric renal transplant for chronic renal failure secondary to hypercalcaemia of unknown origin. A parathyroidectomy was undertaken in the year preceding the renal transplant. Four months prior to ENT referral, he developed intermittent right-sided otorrhoea, accompanied by a decrease in hearing on that side. There were no other symptoms referable to the right ear and no prior otological history of note, other than a longstanding mixed hearing loss of unknown origin in the contralateral ear. Otoscopy of the left ear was normal, while on the right side, a polyp could be seen obstructing the external canal. Culture of the mucopurulent discharge grew gentamicinsensitive Pseudomonas aeruginosa while histology of the

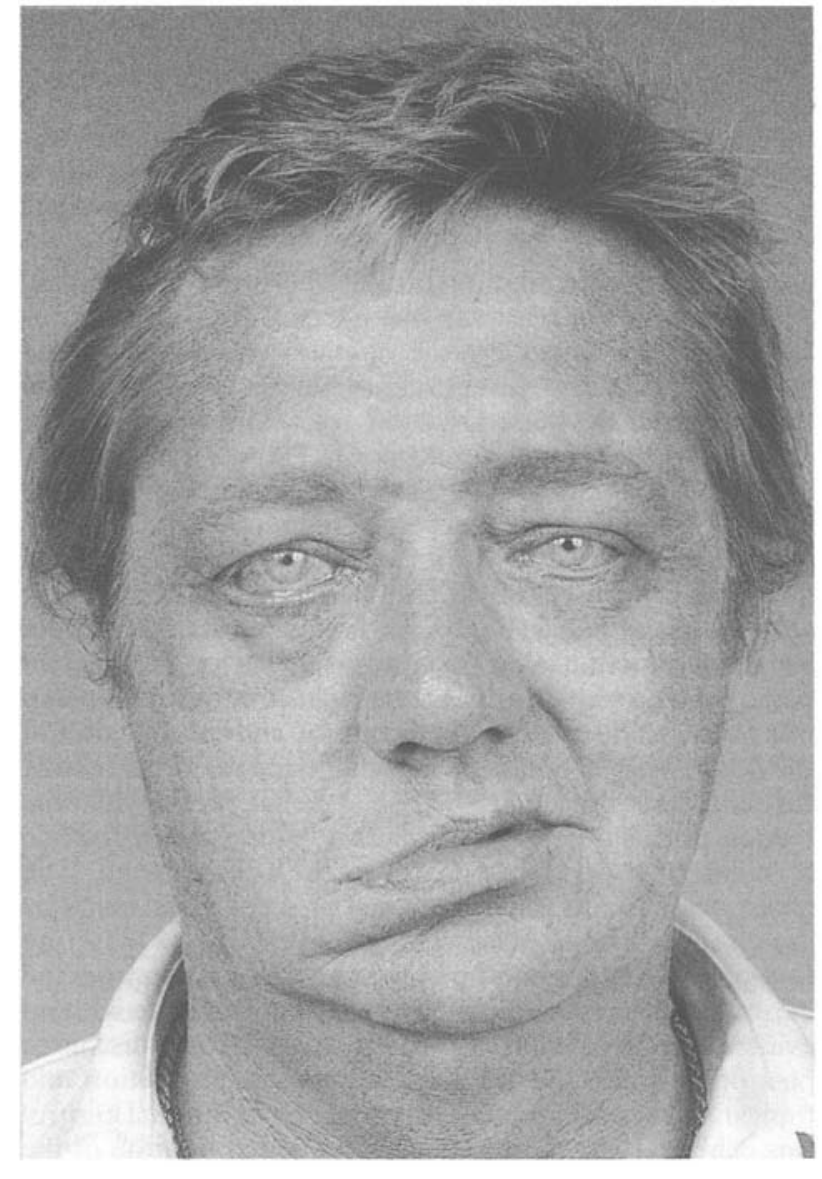

FIG. 1

Pre-operative appearance of right facial palsy (House Grade VI).

From the University Department of Otolaryngology, Manchester Royal Infirmary, Manchester, UK Accepted for publication: 14 April 1995. 


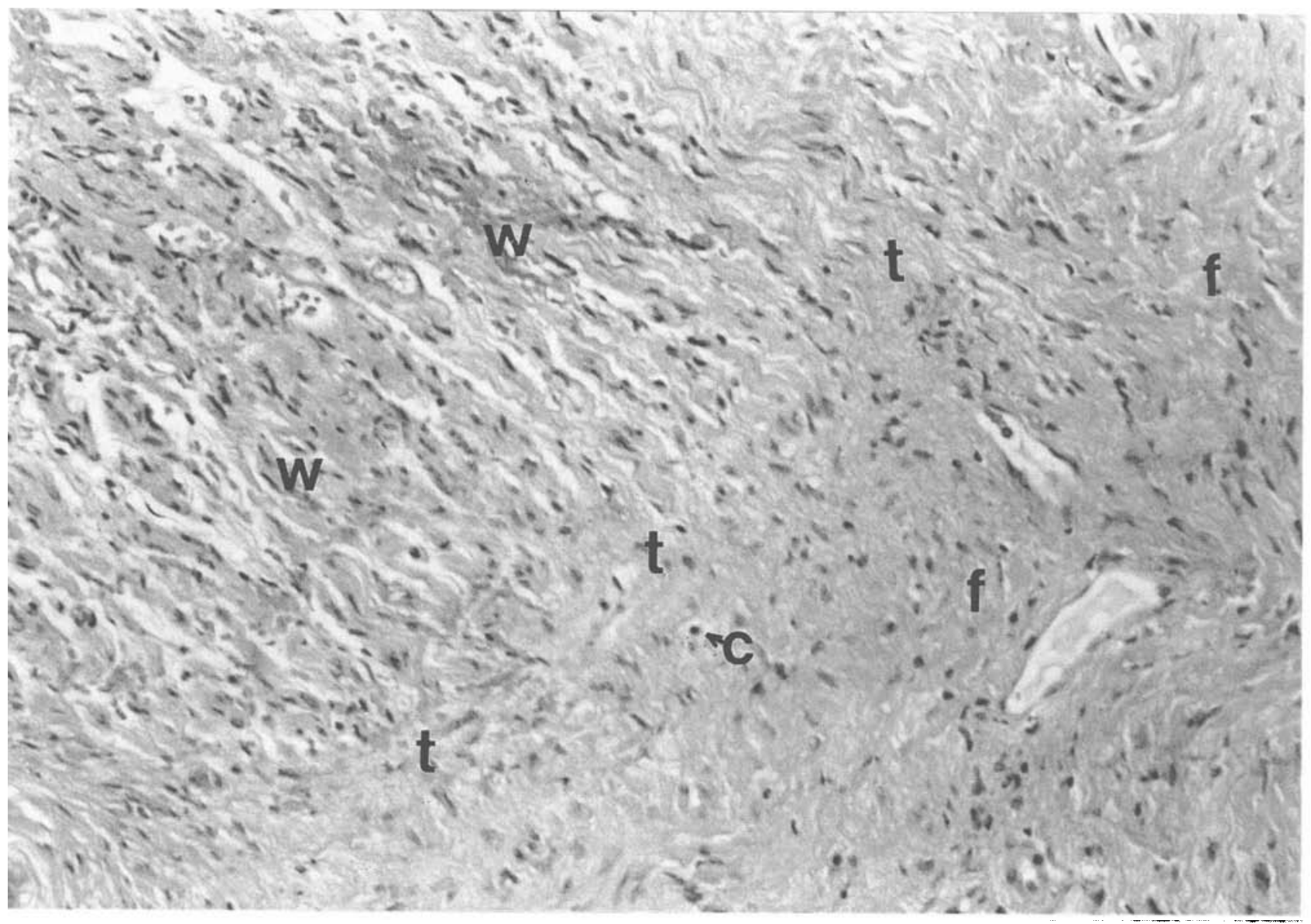

FIG. 2

Histology of proximal facial nerve stump showing wavy nerve fibres (W), terminating (t) abruptly in dense sclerotic fibrous tissue (f) containing scattered chronic inflammatory cells (C).

polyp showed granulation tissue. Following aural toilet. audiometry of the right ear was normal.

The decision to explore the right ear was made, but the patient experienced an episode of severe rejection of the renal transplant which required treatment with azathioprine, prednisolone and cyclosporin. He was subsequently lost to ENT follow-up.

Three months later, he was re-admitted by the renal physicians with a deterioration in renal function and a three-week history of a complete right lower motor neurone facial palsy (Figure 1). Following stabilization of his renal function over the next six weeks, the patient underwent an exploration of the right mastoid. The polyp was found to be eroding the posterior and inferior wall of the deep external meatus. Polypoid tissue filled the middle ear and had breached the facial canal, destroying the section of facial nerve from halfway along the horizontal segment to a point just distal to the second genu. The incus, malleus and stapes arch had also been destroyed by the disease process. A radical mastoid cavity was therefore fashioned. Histology of the polyp and tissue taken from the mesotympanum revealed active granulation tissue with no evidence of neoplasia. The cavity continued to discharge post-operatively and required regular micro-suction and topical treatment. Five months later, once optimal control was achieved. the patient underwent re-exploration of the right ear with repair of the facial nerve using a $15 \mathrm{~mm}$ section of the greater auricular nerve as a cable graft. The histological appearance of the proximal facial nerve stump is shown in Figure 2, demonstrating a surrounding chronic inflammatory cell infiltrate. Subsequent outpatient review revealed initial return of facial function at nine months and when last reviewed, some 12 months after the nerve graft. facial nerve function had improved to House Grade IV (Figure 3).

\section{Discussion}

Facial palsy due to CSOM without cholesteatoma is rare. Such palsies are more frequent when cholesteatoma is present and unless a congenital dehiscence of the fallopian canal exists, must be preceded by a period of bone erosion. The pathogenesis of bone resorption in cholesteatoma is complex, and may involve more than one mechanism. Pressure from a cholesteatomatous sac mav induce osteoclastic activity and lead to dehiscence of a portion of bone over the nerve (Chole. 1988). leading to a slowly progressive facial weakness (McGinn et al. 1986). However, acquired cholesteatoma is usually associated with granulation tissue and infection (Djeric and Savic. 1989), with a number of interlinking mechanisms at the cellular and enzymatic level being responsible for bone resorption. Interleukin-I (IL-I) released from tissue macrophages increases local osteoclast activity and is chemotactic for circulating monocytes and macrophages (Ahn et al., 1990; Schilling et al. 1992). The rapid growth of squamous epithelium, enhanced by the presence of infection (Wells and Michaels. 1991). leads to high numbers of desquamated cells which may further accelerate osteoclastic activation by release of IL-I (Schilling $e t$ al. 1992). Cells of the macrophage/monocyte series may also exhibit osteoclast-like activity, especially if stimulated by cytokines released from polymorphonuclear leucocytes (Maylot et al.. 1991). Interleukin-I is also known to 


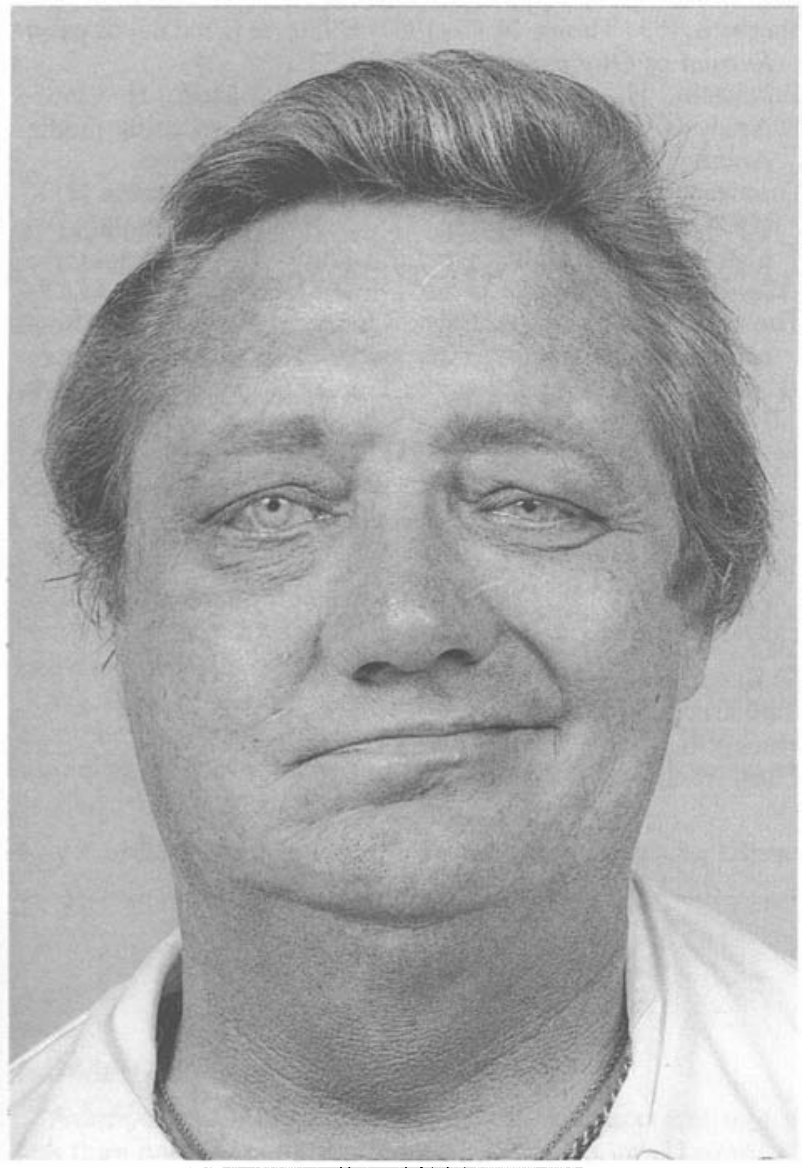

FIG. 3

Post-operative appearance of right facial palsy at 12 months (House Grade IV).

stimulate increased production of collagenase and prostaglandin E2 (PGE2), both of which are produced by bone-resorbing cells (Ahn et al., 1990). Recently, a parathyroid-hormone-like substance has been isolated from cholesteatomata, suggesting a more direct mechanism for bone resorption (Cheshire et al., 1991). Osteoclastic bone resorption may lead to dehiscence of the fallopian canal (Browning, 1987), with subsequent facial paralysis as the infective process involving the facial nerve trunk (Djeric and Savic, 1990). Granulation tissue in association with longstanding infection may lead to polyp formation, impeding drainage via the external auditory meatus and further exacerbating the condition.

Thomsen and his colleagues in their extensive histological and histochemical studies on CSOM, noted that bone resorption occurred whether or not cholesteatoma was present: however, the magnitude of the resorption was greater when cholesteatoma was present (Thomsen et al., 1974; 1981). In cases of non-cholesteatomatous CSOM, many of the factors which precipitate bone resorption still apply. PGE2 has been demonstrated in middle ear granulation tissue to have a similar level of bone resorbing activity to that in cholesteatoma (Kurihara et al., 1991). Infection will activate cells of the polymorph and monocyte/macrophage series whether cholesteatoma is present or not. However, the desquamating cells in cholesteatoma undoubtedly accelerate the immune activation, which may explain the more extensive bone resorption when cholesteatoma is present.

In the case we describe, the disease process was so aggressive as to completely destroy a $15 \mathrm{~mm}$ section of fallopian canal and facial nerve and therefore the possibilities of malignancy or tuberculous otitis media were considered. However, histopathology and microbiol ogy of tissue obtained at the time of operation were negative. In view of the onset of facial palsy during treatment for acute graft rejection. it is likely that the Pseudomonas aeruginosa infection secondary to the patient's compromised immune status was primarily responsible for the extensive nature of the mucosal disease. This may have led to a necrotizing vasculitis, osteitis and neuritis. much as is seen in malignant otitis externa. However, the possibility that hyperparathyroidism enhanced the osteoclastic activity also has to be considered.

Despite the creation of an adequately ventilated radical mastoid cavity, there was persistence of granulation tissue and infection which delayed repair of the facial nerve. This granulation tissue was difficult to eradicate until the immunosuppressants were returned to maintenance levels. The treatment of facial palsy secondary to chronic mucosal otitis media, as when cholesteatoma is present. is surgical. The ear must be explored as soon after the onset of the palsy as possible. with removal of diseased mucosa and creation of adequate drainage and ventilation. To achieve this, open cavity mastoidectomy is frequently necessary (Harker and Pignatari, 1992). With such treatment. the majority of patients can expect complete recovery of facial nerve function, though partial recovery and persistent paralysis have been documented (Savic and Djeric. 1989: Harker and Pignatari. 1992).

\section{Conclusion}

This report describes a case of non-cholesteatomatous facial palsy. Unlike previous reports, the palsy was secondary to complete destruction of a significant segment of the nerve. The extensive nature of the mucosal disease, coincidence with an episode of severe graft rejection suggests that the immunosuppression was significant in the pathogenesis of the facial palsy.

\section{References}

Ahn, J. M., Huang, C. C., Abramson. M. (1990) Interleukin-I causing bone destruction in middle ear cholesteatoma. Otolaryngology-Head and Neck Surgery 103: 527-536.

Browning. G. G. (1987) Pathology of inflammatory conditions of the external and middle ear. In: Scott-Brown's Otolaryngology. 5th Edition. (Kerr, A. G., Booth, J. B., eds.) Butterworths London, pp 53-87.

Cheshire. I. R., Blight, A. Ratcliffe. W. A.. Proops. D. W. Heath. D. A. (1991) Production of parathyroid-hormonerelated protein by cholesteatoma cells in culture. Lancet 338: $1041-1043$.

Chole. R. A. (1988) Osteoclasts in chronic otitis media. cholesteatoma and otosclerosis Annals of Otology, Rhinol ogy and Laryngology 97: 661-666.

De Paep, K., Offeciers, F. E., Van de Heyning. P., Claes, J., Marquet, J. (1989) Tuberculosis in the middle ear: five case reports. Acta Oto-Rhino-Laryngologica Belgica 43: 321-326.

Djeric. D.. Savic. D. (1989) Characteristics of a pathological process in the destroyed tympanic part of the facial canal in chronic otitis media with cholesteatoma. Revue De Layngologie, Otologie, Rhinologie 110: 449-451.

Djeric. D. Savic, D. (1990) Otogenic facial paralysis. A histopathological study. European Archives of Oto-RhinoLaryngology 247: 143-146.

Harker, L. A., Pignatari. S. S. (1992) Facial nerve paralysis secondary to chronic otitis media without cholesteatoma. American Journal of Otology 13: 372-374.

Kurihara, A., Toshima, M., Yuasa, R., Takasaka, T. (1991) Bone destruction mechanisms in chronic otitis media with cholesteatoma: specific production by cholesteatoma tissue in culture of bone-resorbing activity attributable to 
Interleukin-I-alpha. Annals of Otology, Rhinology and Laryngology 100: 989-998.

Lindstrom, C. J., Pincus. R. L., Leavitt, E. B., Urbina, M. C. (1993) Otologic neuro-otologic manifestations of HIVrelated disease. Otolaryngology-Head and Neck Surgery 108: $680-687$.

May, M. (1987) Disorders of the facial nerve. In: Scott-Brown's Otolaryngology. 5th Edition. (Kerr, A. G., Booth, J. B., eds.), Butterworths, London, pp 560-601.

Mayot, D., Bene, M. C., Faure, G. C., Wayoff, M., Perrin, C. (1991) Immunohistologic analysis of the cholesteatoma matrix in children. International Journal of Pediatric Otorhinolaryngology 22: 115-124.

McGinn, M. D., Chole, A., Tinling, S. P. (1986) Bone resorption induced by middle ear implants. Archives of Otolaryngology, Head and Neck Surgery 112: 635-641.

Premachandra, D. J., Radcliffe, G. (1989) Bilateral facial palsy following secretory otitis media. Journal of Laryngology and Otology 103: 685

Savic, D. L. J., Djeric, D. R. (1989) Facial paralysis in chronic suppurative otitis media. Clinical Otolaryngology 14: 515517.

Schilling, V., Bujia, J., Negri, B., Kastenbauer, E. (1992) Interleukin-I-containing cells in cholesteatoma of the middle ear (abstract). Laryngo-Rhino-Otologie 71: 271-275.
Sherwen. P. J., Thong, N. C. (1987) Bilateral facial nerve palsy Journal of Otolaryngology 16: 28-33.

Takahashi, H., Nakamura, H., Yui, M., Mori, H. (1985) Analysis of 50 cases of facial palsy due to otitis media. Archives of Oto-Rhino-Laryngology 241: 163-168.

Thomsen, J.. Jorgensen, M. B., Bretlau, P., Kristensen. H. K. (1974) Bone resorption in chronic otitis media. A histological and ultrastructural study. II: Cholesteatoma. Journal of Laryngology and Otology 88: 983-992.

Thomsen, J., Bretlau, P., Balslev-Joorgensen, M. (1981) Bone resorption in chronic otitis media. The role of cholesteatoma, a must or an adjunct? Clinical Otolaryngology 6: 179186.

Wells, M. D.. Michaels, L. (1991) Mode of growth of acquired cholesteatoma. Journal of Laryngology and Otology 105: 261-267.

Address for correspondence

Mr C. Hartley,

39 Beech Road.

Cale Green,

Stockport,

Cheshire SK3 8HD. 